\title{
Neonatal polycystic encephalomalacia: four new cases and review of the literature
}

\author{
A. M. CHUTOR I A N,R.C. M I CHENER, R. DEFEN D I I, \\ S. K. H I L A L, A N D E. T. G A M B O A
}

From the Department of Neurology (Division of Child Neurology) and Department of Pediatrics, Columbia Presbyterian Medical Center, College of Physicians and Surgeons of Columbia University, New York, New York, USA

SUMMARY Four patients with pathologically documented polycystic cavitation of the brain had an acute illness characterised by stupor, seizures, CSF erythrocytic and monocytic pleocytosis, increased CSF protein, and diminished CSF glucose. The acute phase was followed by chronic decerebation, disappearance of the CSF abnormalities, and radiological evidence of polycystic cavitation of the brain. In one patient Herpes simplex was isolated from a cutaneous vesicle. The CSF abnormalities in the disorder have received scant attention, and have not previously been correlated with the acute and chronic stages. Clearly some cases are associated with Herpes simplex virus. The clinical profile should now be sufficiently distinctive to permit future identification of the aetiology in more neonates.

Wolf and Cowen (1954) reviewed the cerebral atrophies and encephalomalacias of infancy and childhood. One group, "multiple cystic encephalomalacia involving the white matter," presented a fairly uniform clinical picture of a progressive disorder of early infancy culminating, usually within weeks to months, in spastic quadriparesis, dementia, and death. Some infants survived the disorder in a vegetative state, and ultimately succumbed to aspiration or intercurrent infection. At necropsy, widespread gross cavitation and scarring in the central and subcortical white matter of the cerebral hemispheres were present. The disorder was not familial, and no specific aetiology had been defined.

The purpose of this report is to emphasise features of the progressive phase of this disorder not previously considered integral to it. Four new cases are presented. During the acute phase of their illness there were cerebrospinal fluid erythrocytosis and mononuclear pleocytosis. The CSF had a low sugar and raised protein content. After the progressive phase of the illness, these CSF abnormalities resolved. Previous cases of polycystic encephalomalacia from the literature are reviewed

Address for reprint requests: Dr A. M. Chutorian, Department of Neurology, College of Physicians and Surgeons of Columbia University, 710 West 168th Street, New York, NY 10032, USA.

Accepted 10 August 1978 with emphasis on the cerebrospinal fluid abnormalities which we feel are characteristic of this disorder. Possible viral aetiology is discussed.

\section{Case reports}

CASE 1

This girl was born by spontaneous delivery after an uneventful term gestation and weighed $2660 \mathrm{~g}$. She was well until age 21 days when she developed opisthotonos, fever, and rhinorrhoea. Intermittent apnoea and left sided seizures prompted transfer to Babies' Hospital at age 26 days, and similar seizures were observed. She had periodic opisthotonos. The extremities moved well spontaneously, and reflexes were normal. The CSF was consistently abnormal (Table). She was treated with methicillin despite sterile cultures for bacteria, acid-fast bacilli, and fungi. Seizures were controlled but deterioration continued and severe quadriparesis, blindness, and deafness ensued three weeks later. Ventriculography showed dilatation of the third and lateral ventricles with multiple cysts surrounding the lateral ventricles. The head circumference did not increase. No virus was recovered from spinal and ventricular fluids. She died at age four months.

A necropsy was done. The cause of death was peritonitis from a perforated gastric ulcer. When 
Table Neonatal polycystic encephalomalacia-cerebrospinal fluid findings

\begin{tabular}{|c|c|c|c|c|c|c|c|}
\hline \multirow[t]{2}{*}{ Study } & \multirow[t]{2}{*}{$R B C / m^{3}$} & \multirow[t]{2}{*}{$W B C / m^{3}$} & \multirow[t]{2}{*}{ Lymph \% } & \multirow[t]{2}{*}{ Poly \% } & \multirow{2}{*}{$\begin{array}{l}\text { Protein } \\
\text { g/l }\end{array}$} & \multicolumn{2}{|c|}{ Glucose } \\
\hline & & & & & & $m g / d l$ & mmol/l \\
\hline $\begin{array}{l}\text { Young et al. (1965) } \\
\text { Ventricular fluid }\end{array}$ & 2000 & 1270 & 98 & 2 & 9.0 & 15 & 0.83 \\
\hline Haynes et al. (1968) & 2543 & 117 & 94 & 6 & 1.76 & - & - \\
\hline $\begin{array}{l}\text { Charnock and } \\
\text { Cramblett (1970) }\end{array}$ & 111 & 105 & 2 & 98 & 5.4 & 14 & 0.78 \\
\hline Mirra (1971) & - & 600 & 100 & - & 7.0 & - & - \\
\hline $\begin{array}{l}\text { Present Series } \\
\text { Case } 1 \\
\text { Case } 2\end{array}$ & $30-458$ & $26-186$ & 80 & 20 & $2.35-9.7$ & $8-36$ & $0.44-2.0$ \\
\hline Case $3^{\text {Chronic }}$ & $\begin{array}{l}150-1300 \\
0\end{array}$ & $\begin{array}{l}8-30 \\
0\end{array}$ & -90 & 10 & $\begin{array}{l}7.0-11.0 \\
0.28\end{array}$ & $\begin{array}{l}26-48 \\
64\end{array}$ & $\begin{array}{l}1.44-2.66 \\
3.55\end{array}$ \\
\hline $\begin{array}{l}\text { Acute } \\
\text { Chronic }\end{array}$ & $\begin{array}{l}98-128 \\
2\end{array}$ & $\begin{array}{l}94-245 \\
37\end{array}$ & $\begin{array}{r}70 \\
100\end{array}$ & $\begin{array}{r}30 \\
0\end{array}$ & $\begin{array}{l}0.96-6.44 \\
1.1\end{array}$ & $\begin{array}{l}25-32 \\
41\end{array}$ & $\begin{array}{l}1.39-1.78 \\
2.28\end{array}$ \\
\hline $\begin{array}{l}\text { Case } 4 \text { Acute } \\
\quad\end{array}$ & 4-9700 & $90-225$ & 95 & 5 & $1.66-4.9$ & $34-53$ & $1.89-2.94$ \\
\hline
\end{tabular}

the clear fluid in the cavities of the brain was drained, the brain weighed $95 \mathrm{~g}$. The frontal and temporal lobes were reduced to a translucent membrane at the poles and to $2.0 \mathrm{~mm}$ posteriorly. Much of the cortex and most of the white matter were replaced by large spaces of irregular outline, separated by thin tissue bands or membranes. The ventricles were enlarged and smoothly lined. The blood vessels were normal. Microscopically, the only surviving neuroectodermal cells in the frontal and parietal cortices were astrocytes which formed bands of dense fibrillary gliosis along the external and inner surfaces, and also constituted the septa coursing through the gross cavities. Elsewhere, the parenchyma was replaced by small cystic spaces and foci of necrotic debris heavily infiltrated by macrophages and lymphocytes, interspersed with fibrocytes and zones of moderately dense collagen deposition and foci of calcification. In the subarachnoid space only occasional macrophages were identified.

In the brainstem, where changes similar to those above described were encountered, there was glial overgrowth of the aqueductal ependyma but the lumen was patent. The central nuclei, cerebellum, and spinal cord were normal except for secondary degeneration of descending tracts in the latter.

CASE 2

This girl was the product of an uneventful term gestation and delivery, and weighed $3800 \mathrm{~g}$. At age two weeks, she became ill with what was thought to be meningitis. Decerebrate posturing and generalised spasticity developed over the next four weeks. Head circumference advanced from $320 \mathrm{~mm}$ at one month to $435 \mathrm{~mm}$ at four months. When she was admitted to Babies' Hospital there was no social smile, visual tracking, head control, or hand function, and she had severe spastic quadriparesis. On the fourth hospital day, she had right sided seizures. Repeated lumbar punctures yielded abnormal CSF (Table). A combined pneumoencephalogram and ventriculogram (Fig. 1) showed paraventricular cystic loculations. She was discharged after a month with a static head circumference, spastic quadriparesis, blindness, and deafness. One year later she was readmitted because of fever and lethargy. Neurological examination was unchanged. The CSF was normal (Table). She died suddenly on the day of admission.

At necropsy, the right lung showed early bronchopneumonia, and acute and chronic inflammation of the interlobar septa. The brain discharged some $200 \mathrm{ml}$ of clear fluid during removal. Multicameral cavitation replaced most of the cerebral hemispheres, extending to within $10 \mathrm{~mm}$ of the frontal and occipital poles (Fig. 2). Several trabeculae, most of them membrane-thin, divided the cavity into irregular chambers. The ventricles were moderately enlarged. The basal ganglia and diencephalon were considerably diminished in volume. The cortex was average in thickness and the deep nuclei were normal. The blood vessels were not unusual.

The walls and trabeculae (Fig. 3) of the cavities were composed of astroglial tissue. The white matter was rarefied or frankly microcystic. The nerve cell density and cytoarchitecture of the cortex were normal, except for a mild loss of nerve cells in the $\mathrm{H}_{2}$ and $\mathrm{H}_{3}$ fields of the right hippocampus. In the walls of the lateral ventricles there were ependymal nests overgrown by a thickened subependymal glial membrane.

The central nuclei showed a mild to moderate loss of nerve cells and an old astrocytosis. The aqueduct of Sylvius was markedly compressed. In 


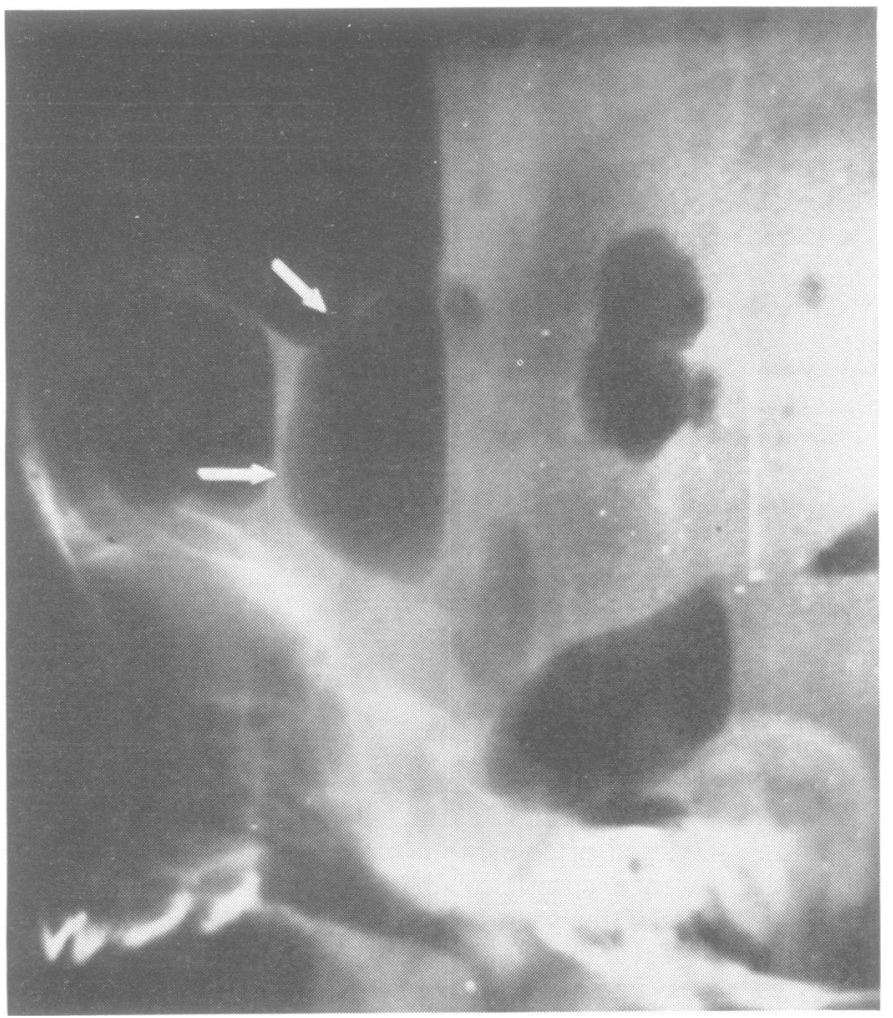

Fig. 1 Pneumoencephalogram (case 2). The lateral view of the ventriculogram shows air in the left frontal horn (arrows). Anterior to the frontal horn there are multiple cystic collections occupying a paraventricular location.

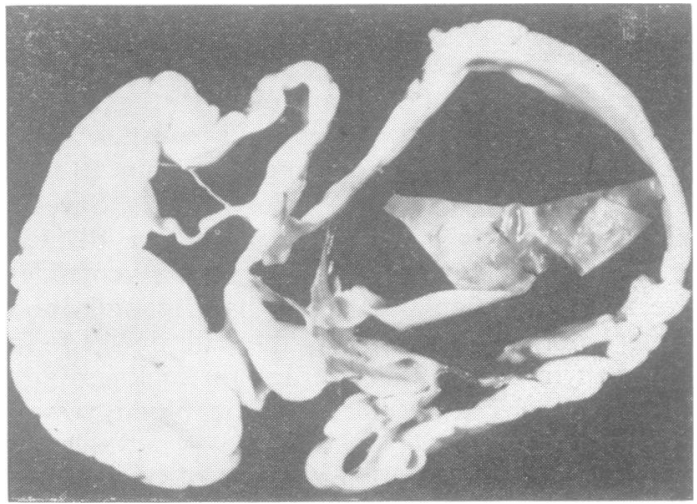

Fig. 2 Coronal section of frontal lobes (case 2), demonstrating asymmetrical bilateral cavitation of the white matter.

its rostral end many ependymal nests and canaliculi were buried in gliofibrillar overgrowth. The cerebellum and spinal cord were essentially normal.

CASE 3

This boy was the $3200 \mathrm{~g}$ product of an uneventful term gestation and delivery. At 10 days of age he

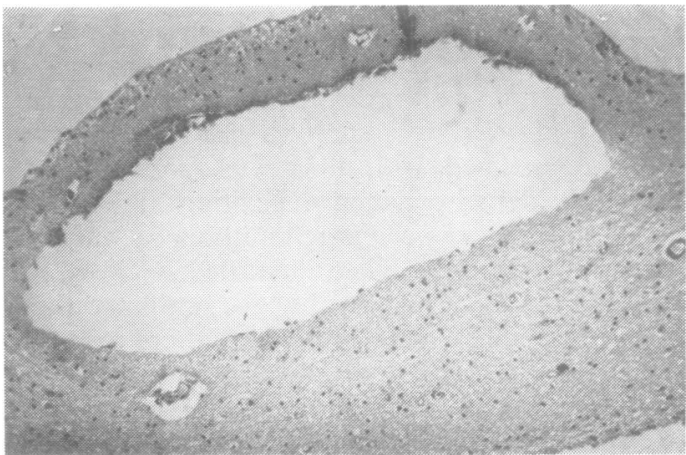

Fig. 3 Photomicrograph of a membranous trabecula dividing a massive cavity (case 2). The membrane consists of old fibrillary gliosis and contains a small cyst. $H$ and $E$, original magnification $\times 130$.

began to feed poorly and developed twitching of all extremities. The CSF was abnormal (Table). Cultures for bacteria were sterile. A dye test for toxoplasmosis, urine examination for cytomegalic inclusion virus, and VDRL were negative. Lethargy and seizures persisted, and he was transferred to Babies' Hospital at one month of age. He had 
frequent generalised seizures, head lag, hypotonia, generalised hyperreflexia, and no response to visual or auditory stimuli. Response to pain was depressed. A progressive quadriparesis followed. The chest radiograph and PPD test for tuberculous infection were normal. Blood and CSF cultures for bacteria, fungi, and tuberculosis were repeatedly negative. No virus was isolated from CSF, throat, saliva, urine, or rectal swabs. There was no toxoplasma fluorescent antibody in CSF. A pneumoencephalogram showed cystic cavitation in the periventricular areas with dilatation of the lateral ventricles.

At 10 weeks, a cerebral biopsy was performed. The cerebral mantle enclosed a cavity that extended into the hemisphere and contained yellowish brown fluids. The neurones and glia in the cortex were replaced by a dense population of macrophages, scattered lymphocytes, occasional fibrocytes and a few multinucleated cells. Small aggregates of calcific stippling were fairly numerous. Underlying bands of white matter contained only astrocytes which were increased in number and hypertrophied. Blood vessels were increased in number and size, but otherwise unremarkable.

Homogenate of the cyst wall was inoculated into the brains of 12 one week old Swiss albino mice which later developed slowing of movements and failure to thrive. Nine animals died after two days of illness. Diffuse cerebral lymphocytic perivascular infiltration was present. No inclusion bodies were seen. Brain suspension from the three remaining mice inoculated into 12 mice caused no illness. Control animals inoculated with diluent alone did not develop any illness. Tissue culture obtained from a portion of the brain biopsy sample showed no cytopathic changes. Trypsinised tissue culture cells failed to produce illness in 10 one week old mice after intracerebral inoculation.

His condition stabilised, and he had a spastic quadriparesis, blindness, and deafness. At this time his CSF abnormalities had partially resolved (Table).

\section{CASE 4}

A 12 day old boy was brought to Babies' Hospital because of decreased appetite and jerking of his limbs. He was the product of an uneventful term gestation and delivery, and he was discharged as normal on the third day. On admission, he was lethargic, and had clonic movements of the left arm. He was afebrile, and the general examination was normal. On the second day he was in status epilepticus. The CSF was abnormal (Table). Culture for bacteria was negative. He required mechanical ventilation for three days. A cutaneous vesicle appeared on the second day and was found to contain Herpes simplex from its cytopathogenic effect in tissue culture. Herpes simplex was also recovered from a swab of the nasopharynx. On the fourth day, the endotracheal tube was removed. $\mathrm{He}$ remained lethargic and unable to suck or swallow. On the 22nd day a computerised tomographic scan showed multiple irregular lucencies throughout the cerebral hemispheres, and mild ventricular dilatation (Fig. 4). At age two months, he was lethargic and required nasogastric tube feeding. Spastic quadriparesis was present. He died suddenly at age $2 \frac{1}{2}$ months. At necropsy the brain collapsed and discharged a large amount of fluid. The cerebrum was largely replaced by many smoothly lined fluid filled irregular cavities. The blood vessels were unremarkable.

\section{Discussion}

In their review of the cerebral atrophies and encephalomalacias of infancy Wolf and Cowen (1954) accepted 38 examples from the literature and added three cases as "multiple cystic encephalomalacia of infancy." The pathology, well exemplified by the four cases described here, clearly points to an intensely destructive process which begins late in fetal life or early in infancy, focuses on the central and subcortical white matter of both cerebral hemispheres, extends into the cortex to a variable degree, and generally spares the subcerebral brain. There is no evidence of developmental malformation. Massive bilateral cavities of the cerebral white matter are filled with semi-liquid material which turns in time to clear fluid. The leptomeninges reflect a mild chronic inflammatory reaction which is not apparently specific. The disease process is not haemorrhagic, the blood vessels and sinuses are normal, and the location of the lesions does not conform to a major arterial distribution. Neonatal onset is typical. Seizures, often focal, are characteristic (Wolf and Cowen, 1954; Ford, 1966). The progressive evolution of spastic quadriparesis, dementia, blindness, and deafness was demonstrated by our patients. Apparent arrest of the process with a severe static encephalopathy occurred in patients 2,3 , and 4 adding additionally documented surviving cases to the few already reported (Edinger and Fischer, 1913; Benda, 1941; Cohen and Kristiansen, 1954).

The cerebrospinal fluid formula has not been correlated specifically with the clinical course in previous reports of patients with polycystic encephalomalacia. The spinal fluid is mentioned in 17 cases (Sternberg, 1930; Stevenson and Mc- 


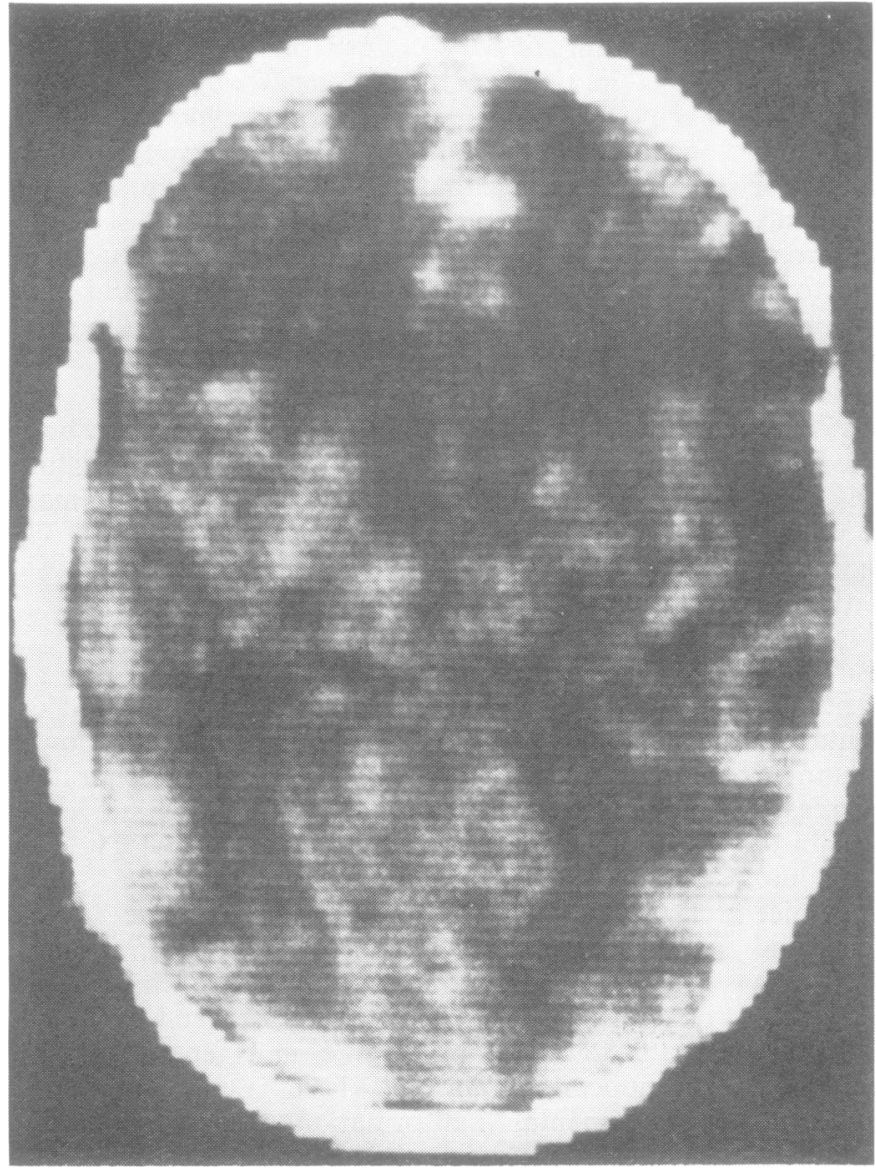

Fig. 4 Computerised tomography scan (case 4) showing multiple cavities in both cerebral hemispheres containing material of fluid density.

Gowan, 1942; Winkelman and Moore, 1942; Marburg and Casamajor, 1944; Lumsden, 1950; Negrin et al., 1952; Cohen and Kristiansen, 1954; Kramer, 1956; Crome, 1958; Lindenberger and Swanson, 1967; Aicardi et al., 1972; Schultz and Leeds, 1973) exclusive of the herpes associated cases. In five instances the fluid is described as "normal", without further detail. The cellular content of the cerebrospinal fluid in these cases varied from 10 to $1450 \mathrm{WBC}$ per $\mathrm{mm}^{3}$, with characteristic lymphocytic preponderance, and erythrocytes ranging to several thousands per $\mathrm{mm}^{3}$. The protein content was recorded five times $0.24 \mathrm{~g} / 1$ (Cohen and Kristiansen, 1954), $0.64 \mathrm{~g} / 1$ (Lumsden, 1950), and, in three of four patients reported by Aicardi et al. (1972), $2.8 \mathrm{~g} / 1,3.2 \mathrm{~g} / 1$, and up to $4.0 \mathrm{~g} / 1$ ). Only three cerebrospinal fluid glucose values are recorded (2.22 mmol/1 (Cohen and Kristiansen 1954), $4.44 \mathrm{mmol} / 1$ (Marburg and Casamajor 1944), and $3.5 \mathrm{mmol} / 1$ (Schultz and Leeds, 1973).

Despite the paucity of cerebrospinal fluid data, review of the case reports (Sternberg, 1930; Marburg and Casamajor, 1944; Ford, 1966) in which a relatively normal cerebrospinal fluid is described suggests that progression of neurological deficit had ceased in these patients. The abnormal CSF values occurred in the active, progressive phase of the disorder (Lumsden, 1950; Negrin et al., 1952; Cohen and Kristiansen, 1954). Case 2 of the present study demonstrates this distinction well, the CSF abnormalities disappearing after the acute illness. The CSF profiles of our four patients are shown in the Table. There was a variable increase in cerebrospinal fluid cells and protein, with diminished glucose content during the active phase of their illness.

Diminished glucose level in the CSF, unlike pleocytosis and raised protein, does not occur characteristically as a result of destructive cerebral lesions (Merritt and Fremont-Smith, 1938) except in the presence of meningeal neoplasia, subarachnoid haemorrhage, and infection. While typical 
of bacterial CNS infections, low CSF glucose levels do occur in viral infections, specifically with neonatal herpes encephalitis (Young et al., 1965; South et al., 1969; Charnock and Cramblett, 1970), and herpes encephalitis in adults (Johnson et al., 1972).

A number of theories have been offered to explain progressive cerebral cavitation in infancy. Peculiarly, theories of infectious origin are lacking. The acute, rapidly progressive, and ultimately self-limiting character of the disorder if the patient survives, so characteristic of infection, has been overlooked by most authors. For example, Ford (1966) records his impression that the disorder is invariably fatal, but examples of patients who survived for a number of years are on record (Edinger and Fischer, 1913; Benda, 1941; Cohen and Kristiansen, 1954), and three of our patients survived the acute insult. Bacterial infections of the central nervous system have been documented in a small number of patients who have shown the pathological changes of multicystic encephalomalacia (Edinger and Fischer, 1913; Stevenson and McGowan, 1942; Winkelman and Moore, 1942; Cohen and Kristiansen, 1954), contrasting with the absence, in the large majority, of evidence of bacterial infection despite vigorous appropriate investigation. The occurrence of bacterial sepsis after the infants have become marasmic is common (Edinger and Fischer, 1913; Stevenson and McGowan, 1942).

The typical gross and histologi_al features of protozoan, bacterial, and tuberculous infection of the nervous system are well known, and do not agree with the pathological findings in infants with polycystic encephalomalacia (Wolf and Cowen, 1954). Whether it is possible for bacterial infection to cause cerebral cavitation culminating in the pathological picture of polycystic encephalomalacia, cannot be established with certainty. The few patients described by Schultz and Leeds (1973) have similar pathological changes, but the descriptions of cerebral tissue in their report are insufficiently detailed to provide conclusive data, and antecedent or concurrent viral infection was not ruled out.

Cerebral lesions produced by viral infection in the developing brain may lack the traditional morphological features of viral infection, resembling degenerations and malformations rather than acute infections of the brain (Raine and Fields, 1973; Kristensson et al., 1974). Bluetongue vaccine virus injected into fetal lambs was followed by the formation of fluid-filled cysts in the subcortical white matter (Osborn et al., 1971).

Four infants with herpes simplex encephalitis reported by Young et al. (1965), Haynes et al. (1968), Charnock and Cramblett (1970), and Mirra (1971), developed cystic degeneration of the brain with a clinical course and CSF findings similar to our four patients (Table). An additional case with serological evidence of CNS infection by Herpes simplex was reported without CSF data (Farris and Blaw, 1973). Erythrocytosis of the cerebrospinal fluid has been emphasised as characteristic of herpes encephalitis in children and adults (Miller et al., 1966; Abramsky et al., 1971) and is common in neonatal herpes encephalitis (Bell and McCormick, 1975). Reduced CSF glucose clearly occurs with herpes encephalitis as noted previously. Herpes simplex virus was isolated from a dermal vesicle and nasopharynx in case 4 . In case 3 a fatal non-bacterial illness developed in mice after intracerebral inoculation of brain biopsy material, while control animals remained well. However, herpes virus was not recovered from the central nervous system of any of our patients.

The clinical profile of a severe progressive encephalopathy associated in the acute phase with CSF leucocytosis, erythrocytosis, raised protein, diminished glucose, and in the quiescent phase with return of the CSF to normal, and with computer assisted tomographic evidence of cystic degeneration of the brain, is sufficiently distinctive to anticipate this clinicopathological entity, so that determination of the aetiology ought to be possible in more neonates.

\section{References}

Abramsky, O., Carmon, A., and Feldman, S. (1971). Cerebrospinal fluid in acute necrotizing encephalitis. Hypochlorrhachia as a diagnostic aid. Journal of the Neurological Sciences, 14, 183-187.

Aicardi, J., Goutieres, F., and Hodebourt de Verbois, A. (1972). Multicystic encephalomalacia of infants and its relation to abnormal gestation and hydranencephaly. Journal of the Neurological Sciences, 15, 357-375.

Bell, W. E., and McCormick, W. F. (1975). Neurologic Infections in Children. Vol. XII Major Problems in Clinical Pediatrics. W. B. Saunders: Philadelphia.

Benda, C. E. (1941). Microcephaly. American Journal of Psychiatry, 94, 1135-1146.

Charnock, E. L., and Cramblett, H. G. (1970). 5Diodo-2-deoxyuridine in neonatal Herpes virus hominis encephalitis. Journal of Pediatrics, 76, 459463.

Cohen, M. D., and Kristiansen, K. (1954). Multiple encephalomalacia of infancy. Acta Psychiatrica et Neurologica, 29, 129-138.

Crome, L. (1958). Multilocular cystic encephalopathy of infants. Journal of Neurology, Neurosurgery, and Psychiatry, 21, 146-152. 
Edinger, L., and Fischer, O. (1913). Ein mensch ohne grosshirn. Pflügers Archiv für die Gesamte Physiologie des Menschen und der Tiere, 152, 535-561.

Farris, W. A., and Blaw, M. E. (1973). Multicystic encephalomalacia in an infant due to Herpes virus hominis type II. Neurology (Minneapolis), 23, 415.

Ford, F. R. (1966). Diseases of the Nervous System in Infancy, Childhood and Adolescence, fifth edition, pp, 225-226. Charles C. Thomas; Springfield, Illinois.

Haynes, R. E., Azimi, P. H., and Cramblett, H. G. (1968). Fatal Herpes virus hominis (Herpes simplex virus) infections in children. Journal of the American Medical Association, 206, 312-319.

Johnson, K. J., Rosenthal, M. S., and Lerner, P. I. 1972). Herpes simplex encephalitis. The course of five virologically proven cases. Archives of Neurology (Chicago), 27, 103-108.

Kramer, W. (1956). Multilocular encephalomalacia. Journal of Neurology, Neurosurgery, and Psychiatry, 19, 209-216.

Kristensson, K., Olsson, Y., and Sourander, P. (1974). Virus encephalitis: pathogenesis in the immature brain. Developmental Medicine and Child Neurology, 16, 382-394.

Lindenberger, R., and Swanson, P. D. (1967). Infantile hydranencephaly. A report of 5 cases of infarction of both cerebral hemispheres in infancy. Brain, 90, 839-850.

Lumsden, C. E. (1950). Multiple cystic softening of the brain in the newborn. Journal of Neuropathology and Experimental Neurology, 9, 119-138.

Marburg, O., and Casamajor, L. (1944). Phlebostasis and phlebothrombosis of the brain in the newborn and in early childhood. Archives of Neurology and Psychiatry (Chicago), 52, 170-188.

Merritt, H. H., and Fremont-Smith, F. (1938). The Cerebrospinal Fluid. W. B. Saunders: Philadelphia.

Miller, J. K., Hesser, F., and Tomkins, V. M. (1966). Herpes simplex encephalitis. Report of 20 cases. Annals of Internal Medicine, 64, 92-103.

Mirra, J. M. (1971). Aortitis and malacoplakia-like lesions of the brain in association with neonatal herpes simplex. American Journal of Clinical Pathology, 56, 104-110.

Negrin, J., Lepow, H., and Miller, B. (1952). Multilocular encephalomalacia. Journal of Neuropathology and Experimental Neurology, 11, 62-68.

Osborn, B. I., Silverstein, A. M., Prendergast, R. A., Johnson, R. T., and Parshall, C. J. (1971). Experimental viral induced congenital encephalopathies. I. Pathology of hydranencephaly and porencephaly caused by bluetongue vaccine virus. Laboratory Investigation, 25, 197-205.

Raine, C. S., and Fields, B. N. (1973). Neurotropic viruses and the developing brain. New York State Medical Journal, 73, 1169-1179.

Schultz, P., and Leeds, N. E. (1973). Intraventricular septations complicating neonatal meningitis. Journal of Neurosurgery, 38, 620-626.

South, M. A., Tompkins, W. A. F., Morris, C. R., and Rauls, W. E. (1969). Congenital malformation of the central nervous system associated with general type (type 2) herpes virus. Journal of Pediatrics, 75, 13-18.

Sternberg, C. (1930). Multiple hohlenbildungen in grosshirn (Markporencephalien) als folgen des Geburststrauma. Beiträge zur Pathologischen Anatomie, 84, 521-528.

Stevenson, L. D., and McGowan, L. E. (1942). Encephalomalacia with cavity formation in infants. Archives of Pathology, 34, 286-300.

Winkelman, N. W., and Moore, M. T. (1942). Progressive degenerative encephalopathy. Archives of Neurology and Psychiatry (Chicago), 48, 54-71.

Wolf, A., and Cowen, D. (1954). The cerebral atrophies and encephalomalacias of infancy and childhood. In Neurology and Psychiatry in Childhood. Research Publications of the Association for Research in Nervous and Mental Diseases, 34, 199-330.

Young, G. F., Knox, D. L., and Dodge, P. R. (1965). Necrotizing encephalitis and chorioretinitis in a young infant. Archives of Neurology (Chicago), 13, 15-24. 